\title{
ANXIETY AND AFFECT IN SUCCESSFUL AND LESS SUCCESSFUL ELITE FEMALE BASKETBALL PLAYERS: IN-SITU SAMPLING BEFORE SIX CONSECUTIVE GAMES
}

\author{
Attila Szabo, Attila Szücs, Zoltán Gáspár, Krisztina Süle \\ Institute of Health Promotion and Sport Sciences \\ Eötvös Loránd University, Budapest, Hungary \\ Address: 10 Bogdánfy, 1117 Budapest, , Hungary. \\ E-mail: szabo.attila@ppk.elte.hu ordrattilaszabo@yahoo.com
}

\begin{abstract}
Justification and aim of the study: Successful athletes tend to approach contest situations with different psychological mind-set than their less successful counterparts. The aim of this repeated-measures design study was to assess whether a successful (national league third rank) and a less successful (11th rank) first division women's basketball team differ in anxiety, positive affect, and negative affect before six consecutive games in the annual championship. Methods: Two psychometrically validated questionnaires, the Sport Competition Anxiety Test (SCAT; Martens et al., 1990) and the Positive Affect Negative Affect Scale (PANAS; Watson, Clark, \& Tellegen, 1988) were used to measure pre-competitive anxiety and positive- and negative affect. The scales were completed by first division female basketball players, who were members of either the successful or the less successful team, before six matches; three played at home and three played away from home. Results: Successful players reported lower anxiety before games (effect size (Cohen's d $=1.2$ ) than less successful players. Both teams displayed more positive affect before the games played at home than before the games played away from home $(d=.44)$. However, ratings of the subjective states varied substantially across the games. Conclusion: The results, interpreted in light of an interactional model (Cerin et al., 2000), show that subjective appraisal of each competition situation yields very specific or unique expectations, which in turn determine the psychological states of the players before the upcoming contest.
\end{abstract}

Key words: athlete, expectation, home field advantage, season, team 


\section{Introduction}

A major striving in sport psychology is to differentiate between successful and less successful athletes with a view on selection, prediction, and psychological skill training. In this quest, numerous scholars have adopted the mental health model (Morgan, 1985) that was forwarded on the basis of results obtained with the Profile of Mood States Inventory (POMS; McNair, Lorr, \& Droppleman, 1992). Accordingly, successful athletes report higher vigour and lower fatigue on the POMS, also connotated as the iceberg profile, than less successful athletes. However, despite becoming textbook material, the mental health model has been challenged nearly two decades ago on the basis of the results of a meta-analysis (Rowley, Landers, Kyllo, \& Etnier, 1995). Later, Beedie, Terry, and Lane (2000) concluded that the model and the POMS may still be useful in predicting performance, but not athletic success. Therefore, mental differences between more- and less-successful athletes deserve attention from other theoretical perspectives and using other instruments as well.

Athletic contest is defined by three situational variables: (a) demands, (b) constraints, and (c) opportunities (Cerin, Szabo, Hunt, \& Williams, 2000). The appraisal of these situational components is a function of personality factors, experiences, and coach-fostered (Becker \& Solomon, 2005) expectations about the actual situation. Subjective appraisal of challenge influences both the mental states and form (i.e., positive or negative affect) and intensity of the emotions (Jones, 1995; Lazarus \& Folkman, 1991). The interactional model for challenge in athletic contest (Cerin et al., 2000) may account for psychological differences between more successful and less successful athletes, because of differences in skills, success, and associated expectations in each of the three contest variables. To date the model did not receive sufficient attention. However, this interactional model could account for differences not only between successful and less successful athletes, but also for mental states generated in relation to various contest situations (i.e., easy-hard, home-away competitions).

There is a general assumption that home field advantage also provides psychological benefits that facilitate athletic performance (Carron, Loughhead, \& Bray, 2005; Courneya \& Carron, 1992; Pollard \& Gómez, 2014; Prieto, Gómez, \& Pollard, 2013). Clear evidence for home field advantage was presented by Pollard and Pollard (2005) who examined the records of 400,000 games played between 1876 and 2003. The take home message of their analysis was that there is a home advantage in professional team sports including National Basketball Association, Major League 
Baseball, National Hockey League, National Football League, and professional soccer league in England. The conclusions were echoed in a more recent meta-analysis based on 30 relevant studies (Jamieson, 2010).

Research also looked at the psychological aspects of the home field advantage in various team and individual sports. In light of Cerin et al.'s (2000) interactional model for competition challenge, the situational advantage risen from the home field should influence athletes' appraisal of the game and the associated expectations. This proposition matches the original model forwarded by Courneya and Carron (1992). The net result of a favourable appraisal, and the emerging emotional response to this appraisal, should be a more positive psychological state before home games in contrast to games played away. However, research findings are rather equivocal.

Many studies failed to reveal evidence for psychological advantage before the games played at home. A 27-day diary study of 12 professional rugby league players, who competed in the Super League, found no statistical differences in self-reported mood states leading up to home or away games (Polman, Nicholls, Cohen, \& Borkoles, 2007). Another study with 15 rugby players reported that the game venue did not affect players' pre-contest mood, as based on two home and two away games (Kerr \& Schaik, 1995). Contradicting these findings, the examination of 100 rugby union players showed that in contrast to away games, home games were associated with lower anxiety and also more positive mood (Terry, Walrond, \& Carron, 1998). The examination of 30 professional soccer players before a game played at home and one away revealed no differences in anxiety before the games played at the different locations (Duffy \& Hinwood, 1997). Similar results emerged in mood measures in another inquiry with five professional soccer players tested before two games played at home and two games away from home (Waters \& Lovell, 2002). Further, in individual sports, 26 alpine skiers reported no differences in pre-contest anxiety or self-confidence at home compared to away (Bray \& Martin, 2003). However, positive results emerged with, 14 ice-hockey players who showed more self-confidence and less anxiety before games played at home in contrast to those that were played away from home (Carré, Muir, Belanger, \& Putnam, 2006). Furthermore, Thuot, Kavouras, and Kenefick (1998) also found higher levels of self-confidence and lower somatic anxiety when 23 high school basketball players competed at home instead of away.

In basketball, the home field advantage - from technical and outcome perspectives - is well established (Gayton \& Coombs, 1995; Silva \& 
Andrew, 1987; Snyder \& Purdy, 1985; Varca, 1980). Bray and Widmeyer (2000) found that team collective efficacy was a critical psychological factor increased by the home advantage. Team quality was also implicated in the home field advantage (Madrigal \& James, 1999). It was found that high quality, or more successful, teams suffered in matches played away from home, whereas less successful teams seemed to profit (Loughead, Carron, Bray, \& Kim, 2003). Thus, research in basketball home field advantage appears to shows that both the situation and quality, or success, of the team could affect athletes' psychological states and, therefore, the ensuing athletic performance.

In the present inquiry, anxiety, positive- and negative affect were gauged before six consecutive (three home and three away) games in a successful and a less successful first division female basketball team. In light of Cerin et al.'s (2000) interactional model, it was hypothesized that as a result of the varying situations, the measures will be more positive during the home than away games, and that further differences between successful and less successful teams may also emerge, with a more favourable profile in the more successful team. It was also presumed that the successful team will exhibit lower anxiety profile as measured with the Sport Competition Anxiety Test (Martens, 1977; Martens, Vealey, \& Burton, 1990).

\section{Material and Methods}

Participants. Elite female basketball teams, playing in the national first division and finishing the past season among the top and bottom third of the league, were invited for participation in the research. Nine players from a relatively successful team (ranked third in the first division) and a 12 players from a less successful team (ranked 11th in the first division) agreed to take part in the study. All players were contracted members of their respective teams. Athletes spoke the same language and had similar social and cultural background. Age of the more successful team was higher $(M=26.3, S D=6.1$ years $)$ than that of the less successful team $(M=21.9$, $S D=4.1$ years). However, the age-difference was statistically not significant. The 21 players have all consented to participation in the inquiry. One player from the less-successful team was excluded from the study due to absences and, hence, lack of data. The final sample consisted of 20 participants. Confidentiality of personal responses was assured. The study was conducted in accord with the local as well as international ethical regulations (i.e., The British Psychological Society, 2010; World Medical Association, 2008).

Measures. The Sport Competition Anxiety Test (SCAT; Martens, 1977; Martens et al., 1990) was adopted for determining competitive 
anxiety. The SCAT contains 15 items; five are dummy and 10 assess anxiety. Eight of the 10 items measure somatic anxiety and two are indices of cognitive anxiety. Therefore, the SCAT is commonly adopted as a somatic-trait instrument. The respondents have to indicate how they usually feel when they compete on a 3-point scale: (a) hardly ever, (b) sometimes, and (c) often. The scale contains statements like: "Just before competing, I notice my heart beats faster than usual," or "Before I compete I am nervous." The letter-codes are transformed into numbers $(a=1, b=2, c=3)$. Two items out of 10 are rated inversely. A total score calculated for the 10 items reflects competitive anxiety. The higher the score, the higher is the anxiety. Martens et al. (1990) reported good psychometric properties for the scale; the internal reliability ranged from .95 to .97 (Cronbach's alpha) and its mean test-retest reliability was .77. The SCAT was used in over 100 inquiries (Dunn \& Dunn, 2001; database searches May, 2013). Despite the contention that the SCAT is a trait measure, its sensitivity to both short and long term intervention-induced changes was shown in the literature (Lohr \& Scogin, 1998; Rani \& Dhadwal, 2013; Singh \& Gaurav, 2011; Smith, Smoll, \& Barnett, 1995).

The Positive Affect Negative Affect Scale (PANAS; Watson, Clark, $\&$ Tellegen, 1988) was used for measuring affect. The 14-item abbreviated version of the scale (Gauvin \& Szabo, 1992) was adopted in the current inquiry for its reliability in past experience sampling research (Gauvin \& Szabo, 1992; Szabo \& Parkin, 2001). This scale consists of six positive items (happy, pleased, energetic, joyful, relaxed, and experiencing enjoyment/fun) and eight negative items (angry/hostile, stressed, irritated, frustrated, guilty, depressed, unhappy, and worried/anxious). Each item is rated on a 7-point Likert scale ranging from 1 (not at all) to 7 (very much). An aggregate score is obtained for both positive and negative items. The PANAS has excellent psychometric properties (Watson \& Clark, 1999; Ostir, Smith, Smith, \& Ottenbacher, 2005. The internal reliabilities obtained in the current study are presented in the Results section and Table 1.

In contrast to the SCAT, the PANAS is a state measure that gauges affect, defined as a non-reflective, but consciously retrievable, psychophysiological mental state bridging emotions and mood (Russell \& Feldman Barrett, 2009).

Procedure. After giving consent for participation, basketball players completed the SCAT and PANAS in the presence of the experimenter within $30 \mathrm{~min}$ before the start of the game. This assessment was repeated before six consecutive matches, played at one-week intervals, during the season. The players completed the two questionnaires near the basketball 
court and during this time they were not allowed to interact with anyone, except if they had a question to the experimenter pertaining to the completion of the questionnaires. The experimenter recorded the nature (home or away) and the outcome (win or loss) of the game. Data were entered in an SPSS data file for subsequent statistical analyses. Sample size based statistical power analysis was performed with the $\mathrm{G}^{*}$ Power software (Faul, Erdfelder, Lang, \& Buchner, 2007). Calculation for repeated measures analysis of variance, mixed between-within interaction design, with a moderate effect size, two groups and six repeated measures, $\alpha$ error $=.05$, with $n=20$, assured less than the optimal (.95) statistical power $(1-\beta$ error $)=.84$. However, it is generally accepted that tests with a power greater than .80 (or $\beta<=.20$ ) may be considered statistically fairly robust (Park, 2008).

\section{Results}

Measures and Variability. The internal reliabilities (IR; Cronbach's alpha) of the three dependent measures were calculated for the six games and are presented in Table 1.

Table 1

Internal reliability (Cronbach's alpha) of the scales at six sampling periods

\begin{tabular}{|c|c|c|c|}
\hline Game & Anxiety & Positive Affect & Negative Affect \\
\hline Game 1 & .85 & .85 & .75 \\
\hline Game 2 & .79 & .87 & .70 \\
\hline Game 3 & .77 & .78 & .53 \\
\hline Game 4 & .84 & .86 & .64 \\
\hline Game 5 & .79 & .84 & .76 \\
\hline Game 6 & .71 & .90 & .70 \\
\hline
\end{tabular}

According to a commonly accepted classification (Kline, 1999) anxiety IR values were in the range of acceptable to good. The IR results for positive affect were mostly in the good category. However, two out of six IR scores for negative affect were in either in the poor or questionable category, whereas the other four fitted into the acceptable range. Due to the low sample size, the current IR values should be considered approximate rather than accurate in spite of the fact that the Cronbach's alpha coefficient appears to change relatively little with an increase in the sample size (Javali, Gudaganavar, \& Raj, 2011). Further, these calculations were aimed at verification rather than psychometric validation.

Correlations, for each instrument, over the six games showed substantial variability with results for anxiety varying between $r=-.02$ to $r=.63$, for positive affect between $r=-.03$ to $r=.80$, and for the negative 
affect values between $r=.16$ to $r=.84$ (Table 2).

Table 2

Correlations (r) between the dependent measures across six games

\begin{tabular}{|c|c|c|c|c|c|c|c|}
\hline & Game 1 & Game 2 & Game 3 & Game 4 & Game 5 & Game 6 & \\
\hline Game 1 & $\begin{array}{l}- \\
- \\
-\end{array}$ & $\begin{array}{l}.59^{*} \\
.50^{*} \\
.60^{*}\end{array}$ & $\begin{array}{l}.13 \\
-.03 \\
.26\end{array}$ & $\begin{array}{l}.56^{*} \\
.62^{*} \\
.79^{*}\end{array}$ & $\begin{array}{l}.42 \\
.44 \\
.67^{*}\end{array}$ & $\begin{array}{l}.13 \\
.52^{*} \\
.73^{*}\end{array}$ & $\begin{array}{l}\text { Anxiety } \\
\text { Positive } \\
\text { Affect } \\
\text { Negative } \\
\text { Affect }\end{array}$ \\
\hline Game 2 & & $\begin{array}{l}- \\
- \\
-\end{array}$ & $\begin{array}{l}-.03 \\
.29 \\
.40\end{array}$ & $\begin{array}{l}.47^{*} \\
.43 \\
.40\end{array}$ & $\begin{array}{l}.33 \\
.80^{*} \\
.84^{*}\end{array}$ & $\begin{array}{l}.63^{*} \\
.42 \\
.39\end{array}$ & $\begin{array}{l}\text { Anxiety } \\
\text { Positive } \\
\text { Affect } \\
\text { Negative } \\
\text { Affect }\end{array}$ \\
\hline Game 3 & & & $\begin{array}{l}- \\
- \\
-\end{array}$ & $\begin{array}{l}.12 \\
.33 \\
.25\end{array}$ & $\begin{array}{l}.45^{*} \\
.32 \\
.45^{*}\end{array}$ & $\begin{array}{l}.05 \\
.28 \\
.16\end{array}$ & $\begin{array}{l}\text { Anxiety } \\
\text { Positive } \\
\text { Affect } \\
\text { Negative } \\
\text { Affect }\end{array}$ \\
\hline Game 4 & & & & $\begin{array}{l}- \\
- \\
-\end{array}$ & $\begin{array}{l}.05 \\
.23 \\
.48^{*}\end{array}$ & $\begin{array}{l}.53^{*} \\
.56^{*} \\
.55^{*}\end{array}$ & $\begin{array}{l}\text { Anxiety } \\
\text { Positive } \\
\text { Affect } \\
\text { Negative } \\
\text { Affect }\end{array}$ \\
\hline Game 5 & & & & & $\begin{array}{l}- \\
- \\
-\end{array}$ & $\begin{array}{l}-.02 \\
.41 \\
.54 *\end{array}$ & $\begin{array}{l}\text { Anxiety } \\
\text { Positive } \\
\text { Affect } \\
\text { Negative } \\
\text { Affect }\end{array}$ \\
\hline Game 6 & & & & & & $\begin{array}{l}- \\
- \\
-\end{array}$ & $\begin{array}{l}\text { Anxiety } \\
\text { Positive } \\
\text { Affect } \\
\text { Negative } \\
\text { Affect }\end{array}$ \\
\hline
\end{tabular}

Note. ${ }^{*}$ Statistically significant $(p<.05)$

Again, the aim of these calculations was to detect variability of the responses across the games rather than to investigate the test-retest reliability of the instruments.

Team Parameters. The more successful basketball team has finished in the third place in the division, lost only two games ( 3 and 6) out of the six played during the inquiry, and displayed statistically significant differences in pre-game anxiety levels (Friedman test; $F_{r}(5)=11.66, p=.04$ ) and negative (but not positive) affect $\left(F_{r}(5)=12.89, p=.02\right)$ across matches in 
the championship. The less successful team has finished 11th in the first division, lost all six consecutive games in the course of the investigation, and reported different levels of positive affect across the six matches $\left(F_{r}(5)\right.$ $=13.54, p=.02)$, while its scores in anxiety and negative affect were statistically not significant.

Team Differences. Team differences in anxiety, positive-, and negative-affect before the six consecutive games in the championship were tested with a 2x6 (Teams by Number of Games) repeated measures MANOVA, with pre-competition anxiety, negative-, and positive-affect being the multivariate dependent measures. This analysis has only disclosed a statistically significant main effect for team-measures, with no main effect for games or game by team interaction $(\Lambda=.526, F(3,16)=4.80, p=.014$, partial eta $\left.^{2}\left(\eta_{\mathrm{p}}{ }^{2}\right)=.47\right)$. Follow-up univariate tests have revealed that the multivariate effect was due to the statistically significant difference in pregame reports of anxiety $\left(F(1,18)=9.79, p=.01, \eta_{\mathrm{p}}{ }^{2}=.352\right.$; Fig. 1$)$.

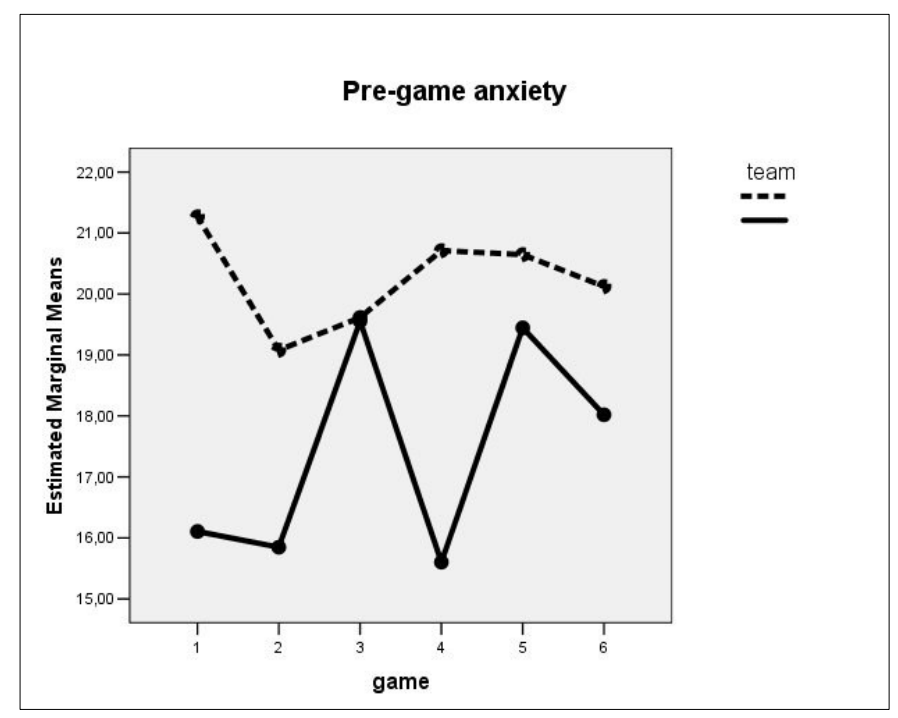

Figure 1. Anxiety as measured with the SCAT in a more successful (continuous line) and less successful (broken line) first division female basketball team over six consecutive championship games.

The more successful team exhibited $17 \%$ lower pre-competition anxiety $\left(M_{\text {aggregate }}=17.43, S D=2.30\right)$ than the less successful team $\left(M_{\text {aggregate }}=20.42, S D=2.04\right)$, effects size, Cohen's $\left.d=1.2\right)$. Two relatively weak trends were also observed in the other dependent measures, with the 
more successful team demonstrating lower negative affect ( $p=.12$; Fig. 2) and higher overall positive affect $(p=.15$; Figure 3 ).

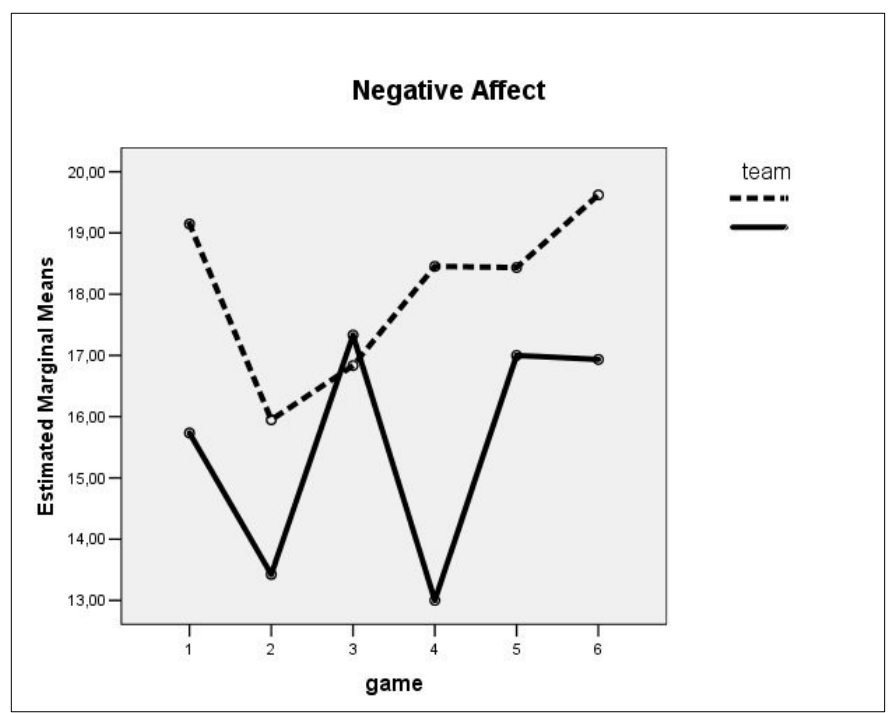

Figure 2. Pre-game negative affect in a more successful (continuous line) and less successful (broken line) first division female basketball team over six consecutive championship games

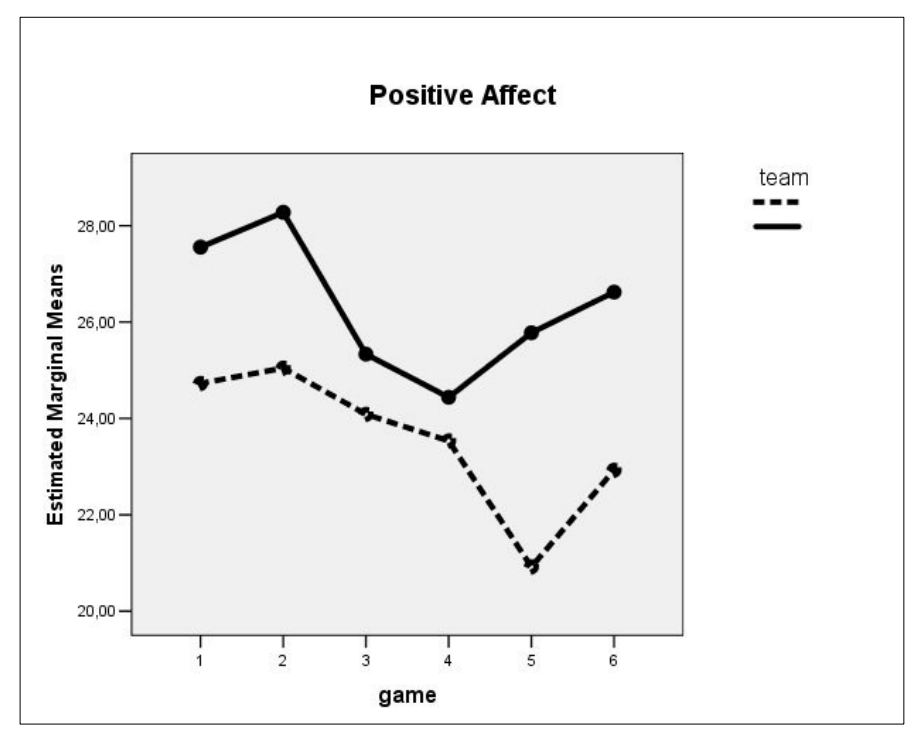

Figure 3. Pre-game positive affect in a more successful (continuous line) and less successful (broken line) first division female basketball team over six consecutive championship games 


\section{Home and Away Matches}

Since in the previous statistical analysis no game by team interaction was disclosed, aggregate score for games played at home and away were calculated, and these scores were subjected to Wilcoxon signed-rank tests for pre-game anxiety, positive affect, and negative affect. Statistically significant difference emerged for positive affect $(Z=-2.56, p=.01 ; M=$ 25.72, $S D=3.71$ at home, and $M=23.88, S D=4.61$ away, respectively; $d=$ $.44)$. A trend in lower negative affect reported before the games played at home $(M=16.49, S D=3.75)$ in contrast to games played away from home $(M=17.40 ; S D=4.16)$ was also noted $(Z=-1.83, p=.07, d=.23)$. The mean values of anxiety were not different between the matches played at home and away.

\section{Won and Lost Games}

The more successful team lost two games out of four: one at home and one away. The measures before these two lost contests (one at home and one away) were compared with the non-parametric Wilcoxon signed-rank tests due to low number of paired observations. These tests were statistically not significant for any of the three dependent measures. However, a further analysis contrasting measures for games won at home and away yielded statistically significant differences for positive affect $(Z=$ - 2.38, $p=.02 ; M=27.92, S D=4.86$ and $M=25.11, S D=4.37$, respectively; $d=.61)$ as well as a trend in scores of anxiety at home $(Z=-$ $1.72, p=.09 ; M=15.97, S D=3.07$ and $M=17.52, S D=2.65$, respectively; $d=.54$ ), showing more positive affect and less anxiety at home than away from home.

\section{Discussion}

The findings in the current research show that there is a psychological advantage in context of the home field basketball contest. They also show a great variability in the ratings of affect and anxiety, pointing to a noteworthy role of situational factors. The psychological states of the more successful team were superior to those of the less successful team. Both the variability of measures and the team-differences could be explained in terms of the pregame appraisals of the contest, the ensuing expectations and the associated feeling states, all in line with Cerin et al.'s (2000) interactional model for competition challenge.

The results of the present inquiry corroborate the scanty reports in the literature that home field advantage is associated with more positive mental states in basketball teams (Bray \& Widmeyer, 2000; Thout et al., 1998). In 
this study elite female basketball players showed a more favourable profile in positive affect and a trend pointing towards lower negative affect prior to games played at home in contrast to games played away. Unlike in an earlier inquiry with high school basketball players (Thout et al., 1998), differences in anxiety could not be detected between home and away games. The discord in findings could be related to the level of the athletes studied (i.e. high school vs. elite) and to different measures used for gauging anxiety (state vs. trait). It should be appreciated that despite of the high response variability, both within and between players, the SCAT is insensitive to cognitive anxiety, because it is tool for measuring somatic anxiety. In line with the interactional model for athletic contest (Cerin et al., 2000), the more positive affectivity before games played at home, regardless of level of success, could be linked to a familiar and/or reassuring (or confidence generating) situation and more pleasant evaluation of the home game environment, resulting in positive affectivity.

The high variability both within and between the teams' responses in both state (affect) and trait (anxiety) measures, strongly supports the notion that pre-competitive emotions need to be studied from an interactional-person, situation or contest, appraisal-expectations - point of view for which a theoretical model presented more than a decade ago by Cerin et al. (2000) appears to be the most appealing. In the current study, the more successful basketball team showed significant variability in anxiety and negative affect, but not scores of positive affect, whereas the less successful team showed statistical significance in the latter measure. This observation suggests that positive affectivity is more homogeneous in the successful team, but negative measures (anxiety and negative affect) may prevail relatively in the less successful team. Consequently, there appears to be a relatively stable positive psychological dominance in successful athletes while the reverse, or a negative mental dominance, may be more characteristic of less successful athletes. This surmise is in agreement with the mental health model (Morgan, 1985) as well.

When team quality was disregarded and correlations were performed between the six (game) ratings of the three dependent measures, the results clearly disclosed high variability, or inconsistency, in the appraisal of the measures across the games. This finding cannot be linked to other factors than the specific expectation associated with each upcoming contest. In accord with the interactional model (Cerin et al., 2000), expectations vary from one game situation to another for a number of reasons, such as: athletes' readiness, coaches' perception of the game and instruction(s) given to the athletes (Becker \& Solomon, 2005), game location (Jamieson, 2010), 
quality of the opponent team (Thout et al., 1998), audiences' expectation (Baumeister et al., 1985), and perceived importance of the contest (Marchant, Morris, \& Anderson, 1998). It is obvious that the interaction of these factors yields different appraisals and expectations in athletes' mind that eventually result in different mental states before every contest (refer to the Figures). This contemplation then purports that home field advantage is only one of the many factors contributing to the situation-generated expectations.

Athletic success may be one of the key determinants of situational expectations and mental responses, but it may have a heavier weight than the other factors. In the current work the results show that more successful elite basketball players demonstrate less anxiety overall (a trait measure) than the less successful athletes. A trend, but reaching only $85 \%$ confidence interval, in more positive affect and less negative affect over six games in the higher quality team has also emerged. While not reaching the conservative levels of statistical significance, this trend should not be ignored because it adds to the overall results of the inquiry revealing that more successful players exhibit more positive mental states before championship contests in general. These findings may be expected and are also self-explanatory, because with a better record (upper third) in the division the more successful team is positively motivated to gain an even better position while the lagging team (bottom third) is negatively motivated to avoid failure and possible drop out from the first division. These collective motivations and individual views of the upcoming contest inevitably result in different appraisal-expectations that trigger situationspecific mental states, in accord with the interactional model for athletic challenge (Cerin et al., 2000).

Affect and anxiety prior to win-loss games could be examined only in the more successful team in the current study (4 wins, 6 losses), because the less successful team has lost all six games during the course of the inquiry. For the four won games an overall more positive affect and a trend in lower anxiety has characterized the home games. For the two lost games, one at home and one away, no differences were found in any of the dependent measures, further affirming that appraisal of the game situation goes beyond the home field advantage. It should be noted, that a more positive affect was a general result also emerging for home games irrespective of team quality. Therefore, the results of the current study show clearly that players' mental states vary with both the game location and quality, or the level of success, of the team. 


\section{Limitations of the Study}

The most striking limitation, also forcing limitations in the type of statistical analyses, was the relatively low sample size investigated in the current research. Indeed, the power in the repeated measures parametric test was only .84 which may be the reason for the inability to demonstrate statistical significance in state measures, which showed strong trends (with $85 \%$ confidence interval) in differentiating more- and less-successful players. Unfortunately, basketball teams are relatively small and not all the members agree to participation, while the involvement of two high and low quality teams - that may increase sample size - would also introduce uncontrollable team-specific factors. Indeed, most investigations examining the psychology of the home field advantage have used relatively low sample sizes, often less than in the current inquiry (Carré et al., 2006; Kerr \& Schaik, 1995; Polman et al., 2007), with a record on the lower end testing only five participants (Waters \& Lovell, 2002). In spite of the relatively low sample size, the current work involved six experiential measures yielding a more thorough picture and assumedly more reliable results in contrast to single assessments.

What may be seen as further limitation is the use of SCAT for measuring anxiety. As noted above the SCAT is rather a somatic and trait measure. If the repeated evaluation of the SCAT results is statistically significant ratings - that has occurred here and in several other studies (Lohr \& Scogin, 1998; Rani \& Dhadwal, 2013; Singh \& Gaurav, 2011; Smith, Smoll, \& Barnett, 1995) - two explanations may be forwarded. The first is that the SCAT is not a "purely" trait measure. The second is that situational appraisal before championship contests is so profound that it even affects how one perceives oneself as a result of a strong trait-state interaction in the evaluation process. Based on current and past results, it is our opinion that the SCAT is not a stable competitive trait anxiety measure, which has implications for past and future inquiries in which SCAT was or will be used as a baseline measure for trait anxiety while researching state anxiety in sport. Finally, the current results are limited to elite female basketball players only. Different results may emerge with males, mixed teams, and in other sports. It is recommended that future studies use experiential sampling with larger teams in which state and trait measures are repeatedly and jointly administered to address the dilemma of dynamic baselines in experiential measurements. For the better understanding of pre-game mental states and the sources of variability, and the connection to performance, Cerin et al.'s (2000) interactional model may prove to be valuable. 


\section{Conclusions}

This study has three contributions: (a) Supports the classical mental health model (Morgan, 1985), more successful elite female basketball players appear to demonstrate more positive mental states before competition than less successful athletes; (b) Regardless of athletic success, home field advantage is linked to more positive affect in elite female basketball players; (c) High variability in psychological trait and state measures reflects the situation-specific appraisal of each game that may results in unique expectations yielding highly variable pattern of mental states prior to competitions, which supports the interactional model for sport challenge (Cerin et al., 2000).

\section{References}

1. Baumeister, R. F., Hamilton, J. C., \& Tice, D. M. (1985). Public versus private expectancy of success: Confidence booster or performance pressure? Journal of Personality and Social Psychology, 48(6), 1447-1457.

2. Baumeister, R. F., \& Steinhilber, A. (1984). Paradoxical effects of supportive audiences on performance under pressure: The home field disadvantage in sports championships. Journal of Personality and Social Psychology, 47(1), 85-93.

3. Becker, A. J., \& Solomon, G. B. (2005). Expectancy information and coach effectiveness in intercollegiate basketball. The Sport Psychologist, 19(3), 251-266.

4. Beedie, C. J., Terry, P. C., \& Lane, A. M. (2000). The Profile of Mood States and athletic performance: Two meta-analyses. Journal of Applied Sport Psychology, 12(1), 49-68. doi:10.1080/10413200008404213

5. Bray, S. R., \& Widmeyer, W. N. (2000). Athletes' perceptions of the home advantage: An investigation of perceived causal factors. Journal of Sport Behaviour, 23(1), 1-10.

6. Bray, S. R., \& Martin, K. A. (2003). The effect of competition location on individual athlete performance and psychological states. Psychology of Sport and Exercise, 4(2), 117-123. doi:10.1016/S1469-0292(01)00032-2

7. Carré, J., Muir, C., Belanger, J., \& Putnam, S. K. (2006). Pre-competition hormonal and psychological levels of elite hockey players: relationship to the 'home advantage'. Physiology \& Behavior, 89(3), 392-398. doi:10.1016/j.physbeh.2006.07.011

8. Carron, A., Loughhead, T., \& Bray, S. (2005). The home advantage in sport competitions: Courneya and Carron's (1992). conceptual framework a decade later. Journal of Sports Sciences, 23(4), 395-407. doi:10.1080/02640410400021542

9. Cerin, E., Szabo, A., Hunt, N., \& Williams, C. (2000). Temporal patterning of competitive emotions: a critical review. Journal of Sport Sciences, 18, 605-625. doi:10.1080/02640410050082314 
10. Courneya, K. S., \& Carron, A. V. (1992). The home advantage in sport competitions: A literature review. Journal of Sport and Exercise Psychology, 14, 13-27.

11. Duffy, L. J., \& Hinwood, D. P. (1997). Home field advantage: Does anxiety contribute?. Perceptual and Motor Skills, 84(1), 283-286. doi:10.2466/pms.1997.84.1.283

12. Dunn, J. G., \& Dunn, J. C. (2001). Relationships among the Sport Competition Anxiety Test, the Sport Anxiety Scale, and the Collegiate Hockey Worry Scale. Journal of Applied Sport Psychology, 13(4), 411429. doi:10.1080/104132001753226274

13. Faul, F., Erdfelder, E., Lang, A. G., \& Buchner, A. (2007). G*Power 3: A flexible statistical power analysis program for the social, behavioral, and biomedical sciences. Behavior Research Methods, 39, 175-191.

14. Gauvin, L., \& Szabo, A. (1992). Application of the experience sampling method to the study of the effects of exercise withdrawal on well-being. Journal of Sport and Exercise Psychology, 14, 361-361.

15. Gayton, W. F., \& Coombs, R. (1995). The home advantage in high school basketball. Perceptual and Motor Skills, 81(3f), 1344-1346. doi:10.2466/pms.1995.81.3f.1344

16. Jamieson, J. P. (2010). The Home Field Advantage in Athletics: A MetaAnalysis. Journal of Applied Social Psychology, 40(7), 1819-1848. doi:10.1111/j.1559-1816.2010.00641.x

17. Javali S. B., Gudaganavar, N. V., \& Raj, S. M. (2011). Effect of Varying Sample Size in Estimation of Coefficients of Internal Consistency. WebmedCentral BIOSTATISTICS, 2(2):WMC001649. Retrieved from http://www.webmedcentral.com/article_view/1649

18. Jones, G. (1995). More than just a game: Research developments and issues in competitive anxiety in sport. British Journal of Psychology, 86, 449-478. doi: 10.1111/j.2044-8295.1995.tb02565.x

19. Kerr, J. H., \& van Schaik, P. (1995). Effects of game venue and outcome on psychological mood states in rugby. Personality and Individual Differences, 19(3), 407-410. doi:10.1016/0191-8869(95)00044-7

20. Kline, P. (1999). The handbook of psychological testing (2nd ed.). London, UK: Routledge.

21. Lazarus, R.S., \& Folkman, S. (1991). The concept of coping. In A. Monat, \& R. S. Lazarus (Eds.), Stress and Coping (pp. 189-206). New York, NY: Columbia University Press.

22. Loughead, T. M., Carron, A. V., Bray, S. R., \& Kim, A. J. (2003). Facility familiarity and the home advantage in professional sports. International Journal of Sport and Exercise Psychology, 1(3), 264-274. doi:10.1080/1612197X.2003.9671718

23. Lohr, B. A., \& Scogin, F. (1998). Effects of self-administered visuo-motor behavioral rehearsal on sport performance of collegiate athletes. Journal of Sport Behavior, 21(2), 206-218. 
24. Madrigal, R., \& James, J. (1999). Team quality and the home advantage. Journal of Sport Behavior, 22(3), 381-398.

25. Marchant, D. B., Morris, T., \& Anderson, M. B. (1998). Perceived importance of outcome as a contributing factor in competitive state anxiety. Journal of Sport Behavior, 21(1), 71-91.

26. Martens, R. (1977). Sport Competition Anxiety Test. Champaign, IL: Human Kinetics.

27. Martens, R., Vealey, R. S., \& Burton, D. (1990). Competitive anxiety in sport. Champaign, IL: Human Kinetics.

28. McNair, D.M., Lorr, M., \& Droppleman, L.F. (1992). Revised Manual for the Profile of Mood States. San Diego, CA: Educational and Industrial Testing Services.

29. Morgan, W. P. (1985). Selected psychological factors limiting performance: A mental health model. In D. H. Clarke and H. M. Eckert (Eds.), Limits of Human Performance (pp. 70-80). Champaign, IL: Human Kinetics.

30. Ostir, G. V., Smith, P. M., Smith, D., \& Ottenbacher, K. J. (2005). Reliability of the Positive and Negative Affect Schedule (PANAS) in medical rehabilitation. Clinical Rehabilitation, 19(7), 767-769. doi:10.1191/0269215505cr8940a

31. Park, H. M. (2008). Hypothesis Testing and Statistical Power of a Test. Working Paper. The University Information Technology Services (UITS), Center for Statistical and Mathematical Computing, Indiana University. Retrieved from http://www.indiana.edu/ statmath/stat/all/power/index.html

32. Polman, R., Nicholls, A. R., Cohen, J., \& Borkoles, E. (2007). The influence of game location and outcome on behaviour and mood states among professional rugby league players. Journal of Sports Sciences, 25(13), 1491-1500. doi:10.1080/02640410601175436

33. Pollard, R., \& Gómez, M. A. (2014). Components of home advantage in 157 national soccer leagues worldwide. International Journal of Sport and Exercise Psychology, (ahead-of-print), 1-16.

34. Pollard, R., \& Pollard, G. (2005). Long-term trends in home advantage in professional team sports in North America and England (1876-2003). Journal of Sports Sciences, 23(4), 337-350. doi:10.1080/02640410400021559

35. Prieto, J., Gómez, M. Á., \& Pollard, R. (2013). Home Advantage in Men's and Women's Spanish First and Second Division Water Polo Leagues. Journal of Human Kinetics, 37(1), 137-143.

36. Rani, S., \& Dhadwal, M. K. (2013). Comparison of pre-competitive and post-competitive anxiety level of inter-collegiate football players. International Journal of Movement Education and Social Sciences 2(1), 13. Retrieved from http://www.ijmess.org/paper/1.\%20Dr.\%20Sangeeta\%20Rani.pdf 
37. Rowley, A., Landers, D., Kyllo, L., \& Etnier, J. (1995). Does the iceberg profile discriminate between successful and less successful athletes? A metaanalysis. Journal of Sport \& Exercise Psychology, 17, 185-199.

38. Russell, J.A, \& Feldman Barrett, L. (2009). Core affect. In D. Sander, \& K. R. Scherer (Eds.), The Oxford companion to emotion and the affective sciences (p. 104). New York, NY: Oxford University Press.

39. Silva, J. M., \& Andrew, J. A. (1987). An analysis of game location and basketball performance in the Atlantic Coast Conference. International Journal of Sport Psychology, 18, 188-204.

40. Smith, R. E., Smoll, F. L., \& Barnett, N. P. (1995). Reduction of children's sport performance anxiety through social support and stress-reduction training for coaches. Journal of Applied Developmental Psychology, 16(1), 125-142. doi:10.1016/0193-3973(95)90020-9

41. Singh, A., \& Gaurav, V. (2011). A Study of Pre-Competitive and PostCompetitive Anxiety Level of Inter-collegiate Volleyball Players. International Journal of Sports Science and Engineering, 5(4), 237-241. Retrieved from

http://www.worldacademicunion.com/journal/SSCI/SSCIvol05no04paper07. pdf

42. Snyder, E. E., \& Purdy, D. A. (1985). The home advantage in collegiate basketball. Sociology of Sport Journal, 2, 352-356.

43. Szabo, A., \& Parkin, A. M. (2001). The psychological impact of training deprivation in martial artists. Psychology of Sport and Exercise, 2(3), 187199. doi:10.1016/S1469-0292(01)00004-8

44. Terry, P. C., Walrond, N., \& Carron, A. V. (1998). The influence of game location on athletes' psychological states. Journal of Science and Medicine in Sport, 1(1), 29-37. doi:10.1016/S1440-2440(98)80006-6

45. The British Psychological Society (2010). Code of Human Research Ethics. Retrieved from

http://www.bps.org.uk/sites/default/files/documents/code_of_human_researc h_ethics.pdf

46. Thuot, S. M., Kavouras, S. A., \& Kenefick, R. W. (1998). Effect of perceived ability, game location, and state anxiety on basketball performance. Journal of Sport Behavior, 21, 311-321.

47. Varca, P. E. (1980). An analysis of home and away game performance of male college basketball team. Journal of Sport Psychology, 2, 245-257.

48. Ward, K. D. (2006). Mood States of Female Collegiate Softball Players. Doctoral dissertation, Oklahoma State University. Retrieved from http://139.78.48.197/utils/getfile/collection/theses/id/3562/filename/3563.pd $\mathrm{f}$

49. Waters, A., \& Lovell, G. (2002). An examination of the homefield advantage in a professional English soccer team from a psychological standpoint. Football Studies, 5(1), 46-59. Retrieved from http://library.la84.org/SportsLibrary/FootballStudies/2002/FS0501f.pdf 
50. Watson, D., \& Clark, L. A. (1999). The PANAS-X: Manual for the positive and negative affect schedule-expanded form. Iowa City, IS: University of Iowa.

51. Watson, D., Clark, L. A., \& Tellegen, A. (1988). Development and validation of brief measures of positive and negative affect: The PANAS scales. Journal of Personality and Social Psychology, 54(6), 1063-1070.

52. World Medical Association (2008). World Medical Association Declaration of Helsinki: Ethical Principles for Medical Research Involving Human Subjects. Retrieved from:

http://www.wma.net/en/30publications/10policies/b3/17c.pdf

Submitted: July 21, 2014

Accepted: December 9, 2014 